\title{
Myosin Light Chain Kinase Accelerates Vesicle Endocytosis at the Calyx of Held Synapse
}

\author{
Hai-Yuan Yue and Jianhua Xu \\ Institute of Molecular Medicine and Genetics and Department of Neurology, Medical College of Georgia, Georgia Regents University, Augusta, Georgia \\ 30912
}

Neuronal activity triggers endocytosis at synaptic terminals to retrieve efficiently the exocytosed vesicle membrane, ensuring the membrane homeostasis of active zones and the continuous supply of releasable vesicles. The kinetics of endocytosis depends on Ca ${ }^{2+}$ and calmodulin which, as a versatile signal pathway, can activate a broad spectrum of downstream targets, including myosin light chain kinase (MLCK). MLCK is known to regulate vesicle trafficking and synaptic transmission, but whether this kinase regulates vesicle endocytosis at synapses remains elusive. We investigated this issue at the rat calyx of Held synapse, where previous studies using whole-cell membrane capacitance measurement have characterized two common forms of $\mathrm{Ca}^{2+} /$ calmodulin-dependent endocytosis, i.e., slow clathrin-dependent endocytosis and rapid endocytosis. Acute inhibition of MLCK with pharmacological agents was found to slow down the kinetics of both slow and rapid forms of endocytosis at calyces. Similar impairment of endocytosis occurred when blocking myosin II, a motor protein that can be phosphorylated upon MLCK activation. The inhibition of endocytosis was not accompanied by a change in $\mathrm{Ca}^{2+}$ channel current. Combined inhibition of MLCK and calmodulin did not induce synergistic inhibition of endocytosis. Together, our results suggest that activation of MLCK accelerates both slow and rapid forms of vesicle endocytosis at nerve terminals, likely by functioning downstream of $\mathrm{Ca}^{2+} /$ calmodulin.

Key words: capacitance; endocytosis; myosin; myosin light chain kinase; the calyx of Held; vesicle

\section{Introduction}

At synaptic terminals, neuronal firing triggers vesicle exocytosis, which is followed by endocytosis to retrieve vesicle membrane. Endocytosis maintains the homeostasis of terminal membrane and recycles vesicles to sustain neurotransmission. Synaptic endocytosis is activity dependent and requires $\mathrm{Ca}^{2+}$ influx through voltage-gated $\mathrm{Ca}^{2+}$ channels on the plasma membrane (Sankaranarayanan and Ryan, 2001; Hosoi et al., 2009; Wu et al., 2009; Yamashita et al., 2010). In addition to synaptotagmin (Poskanzer et al., 2003; Yao et al., 2012), calmodulin is considered a primary $\mathrm{Ca}^{2+}$ sensor in endocytosis (Wu et al., 2009; Sun et al., 2010; Yamashita et al., 2010). Inhibition of calmodulin impairs different forms of endocytosis at the calyx of Held, including rapid endocytosis with a time constant of $\sim 2 s$ and slow clathrinmediated endocytosis with a time constant of seconds to tens of seconds (Wu et al., 2009; Yamashita et al., 2010; Yao and Sakaba, 2012). In hippocampal neurons, knockdown of calmodulin expression decreases endocytosis rate (Sun et al., 2010). These observations further highlight calmodulin as a versatile $\mathrm{Ca}^{2+}$ sensor to regulate distinct synaptic functions including endocytosis, ion

Received Aug. 31, 2013; revised Nov. 7, 2013; accepted Nov. 19, 2013.

Author contributions: J.X. designed research; H.-Y.Y. and J.X. performed research; H.-Y.Y. and J.X. analyzed data; J.X. wrote the paper.

This work has been supported by the start-up fund from Georgia Regents University. We thank Drs. Darrell Brann and Quan-Sheng Du for providing constructive comments on this manuscript.

Correspondence should be addressed to Jianhua Xu, Medical College of Georgia, Georgia Regents University, Augusta, GA 30912. E-mail: jxu1@gru.edu.

DOI:10.1523/JNEUROSCI.3744-13.2014

Copyright $\odot 2014$ the authors $\quad 0270-6474 / 14 / 340295-10 \$ 15.00 / 0$ channel modulation (Xu and Wu, 2005; Dick et al., 2008; Catterall et al., 2013), vesicle replenishment (Sakaba and Neher, 2001), and synaptic plasticity (Lee et al., 2010). One downstream target of $\mathrm{Ca}^{2+}$ /calmodulin is myosin light chain kinase (MLCK), which can phosphorylate the regulatory light chain of myosin (Nairn and Picciotto, 1994). Requirement of MLCK/myosin for presynaptic functions was first reported in sympathetic neurons (Mochida et al., 1994), followed by many studies demonstrating its regulation of synaptic strength and plasticity. For example, inhibitors of MLCK/myosin impair vesicle mobilization in hippocampal neurons (Ryan, 1999), disrupt high-frequency neuromuscular transmission (Polo-Parada et al., 2005; Seabrooke and Stewart, 2011), and prevent the increase of a readily releasable pool after tetanus stimulation in the immature calyx of Held (Lee et al., 2008). Furthermore, MLCK inhibitors increase the number of fast-releasing vesicles and facilitate basal neurotransmission in the calyx (Srinivasan et al., 2008; Lee et al., 2010). These effects indicate a regulatory role of MLCK in vesicle supply and neurotransmission. However, it remains unclear whether MLCK modulates synaptic vesicle endocytosis, which both contributes to vesicle supply and depends on $\mathrm{Ca}^{2+}$ /calmodulin.

To determine the involvement of MLCK in synaptic endocytosis, we investigated effects of specific MLCK/myosin inhibitors on both slow and rapid forms of endocytosis at the calyx of Held, which can be readily resolved with the whole-cell membrane capacitance measurement. In our tests, MLCK inhibitory peptide 18 (MLCKip), ML-7, and wortmannin all decreased the kinetics 
of slow and rapid endocytosis and the efficiency of membrane recovery. Blocking myosin II activity with $(S)$-(-)-blebbistatin (blebbistatin) induced similar inhibition of endocytosis. The effects on endocytosis were not accompanied by changes in exocytosis and $\mathrm{Ca}^{2+}$ channel current. Our results thus suggest that MLCK/myosin facilitates endocytosis at synapses downstream of $\mathrm{Ca}^{2+}$ entry and exocytosis.

\section{Materials and Methods}

Slice preparation. We prepared parasagittal brainstem slices containing the medial nucleus of the trapezoid body (MNTB; Xu and Wu, 2005) in accordance with guidelines of The Institutional Animal Care and Use Committee, Georgia Regents University. Brainstems were acquired from acutely decapitated 7- to 10-d-old Sprague Dawley rats of either sex, and chilled in ice-cold low $\mathrm{Ca}^{2+}$ artificial CSF (aCSF), which contained (in mM): $125 \mathrm{NaCl}, 25 \mathrm{NaHCO}_{3}, 2.5 \mathrm{KCl}, 1.25 \mathrm{NaH}_{2} \mathrm{PO}_{4}, 3 \mathrm{MgCl}_{2}, 0.5$ $\mathrm{CaCl}_{2}, 25$ glucose, $0.4 \mathrm{Na}$ ascorbate, 3 myo-inositol, and $2 \mathrm{Na}$ pyruvate, $\mathrm{pH} \sim 7.4$ when bubbled with $95 \% \mathrm{O}_{2}$ and $5 \% \mathrm{CO}_{2}$. Slices $(180-200 \mu \mathrm{m}$ thick) were sectioned using an automated VT1200S slicer (Leica Microsystems) and transferred into normal aCSF to recover at $37^{\circ} \mathrm{C}$ for $45 \mathrm{~min}$ before being left under room temperature $\left(22-24^{\circ} \mathrm{C}\right)$. The normal aCSF was identical to the low $\mathrm{Ca}^{2+}$ aCSF except that it contained $1 \mathrm{~mm} \mathrm{MgCl}_{2}$ and $2 \mathrm{~mm} \mathrm{CaCl}_{2}$.

Electrophysiology. Using the standard whole-cell patch-clamping technique ( $\mathrm{Xu}$ and $\mathrm{Wu}, 2005$; $\mathrm{Xu}$ et al., 2008), we measured membrane capacitance of the calyx of Held terminals in brainstem slices with either an EPC-10/2 amplifier or an EPC-9 amplifier controlled by the Patchmaster and Pulse program (HEKA), respectively. Capacitance was measured using a software lock-in function based on the Lindau-Neher method (Lindau and Neher, 1988), with a sinusoidal wave $(60 \mathrm{mV}$ peakto-peak amplitude, $1000 \mathrm{~Hz}$ ) being superimposed on a holding potential of $-80 \mathrm{mV}$. The resulting capacitance data were sampled at $1 \mathrm{kHz}$ without averaging, while membrane current was sampled at $20 \mathrm{kHz}$ after an online Bessel filtering of $2.9 \mathrm{kHz}$. Ca ${ }^{2+}$ current, exocytosis, and endocytosis were evoked and analyzed during 4-12 min after establishing the whole-cell configuration. The bath solution contained the following (in mM): $105 \mathrm{NaCl}, 20$ TEA-Cl, $2.5 \mathrm{KCl}, 1 \mathrm{MgCl}_{2}, 2 \mathrm{CaCl}_{2}, 25 \mathrm{NaHCO}_{3}, 1.25$ $\mathrm{NaH}_{2} \mathrm{PO}_{4}, 25$ glucose, $0.4 \mathrm{Na}$ ascorbate, 3 myo-inositol, $2 \mathrm{Na}$ pyruvate, 0.001 tetrodotoxin, and $0.13,4$-diaminopyridine. The solution was $300-$ $310 \mathrm{mOsm}$, and $\mathrm{pH} 7.4$ when bubbled with $95 \% \mathrm{O}_{2}$ and $5 \% \mathrm{CO}_{2}$. The standard presynaptic pipette solution contained (in $\mathrm{mm}$ ): 125 Csgluconate, $20 \mathrm{CsCl}, 4 \mathrm{MgATP}, 10 \mathrm{Na}_{2}$-phosphocreatine, $0.3 \mathrm{GTP}, 10$ HEPES, 0.05 BAPTA (1,2-bis(2-aminophenoxy)ethane- $N, N, N^{\prime}, N^{\prime}-$ tetraacetic acid), $310-320 \mathrm{mOsm}, \mathrm{pH}$ adjusted to 7.2 with $\mathrm{CsOH}$. As needed, the pipette solution was added with wortmannin (Abcam), MLCKip (sequence: RKKYKYRRK), dynamin inhibitory peptide (DYNip, sequence: QVPSRPNRAP), ML-7, blebbistatin, cyclosporin A (all from Tocris Bioscience), or calmodulin binding domain (CBD; sequence: LKKFNARRKLKGAILTTMLA; EMD Millipore Chemicals). The series resistance $(6-15 \mathrm{M} \Omega$ ) was compensated by $50-65 \%$ with a lag of $10 \mu \mathrm{s}$. For recording postsynaptic responses, the principal neuron of MNTB was voltage-clamped at $-80 \mathrm{mV}$ by a patch pipette filled with the following (in mM): $125 \mathrm{~K}$-gluconate, $20 \mathrm{KCl}, 4 \mathrm{MgATP}, 10 \mathrm{Na}_{2}$-phosphocreatine, 0.3 GTP, 10 HEPES, 0.5 EGTA, pH 7.2 (adjusted with KOH). The series resistance $(5-15 \mathrm{M} \Omega$ ) was compensated typically by $80 \%$ with a lag of 10 $\mu \mathrm{s}$. The bath solution was added with $100 \mu \mathrm{M}$ cyclothiazide, $1 \mu \mathrm{M}$ strychnine chloride, and $10 \mu \mathrm{M}$ bicuculline methiodide (all from Abcam) to block AMPA receptor desensitization, and postsynaptic currents mediated by glycine and GABA receptors, respectively. Recordings were made at room temperature $\left(22-24^{\circ} \mathrm{C}\right)$.

Data analysis. The amount of exocytosis $\left(\Delta C_{\mathrm{m}}\right)$ was measured as the difference between the averaged membrane capacitance $\left(C_{\mathrm{m}}\right)$ baseline before the stimulation and the peak of $C_{\mathrm{m}}$ transient. The initial rate of endocytosis, Rate_endo, was measured as the linear rate within the first $4 \mathrm{~s}$ of $C_{\mathrm{m}}$ decay following depolymerizaion for $20 \mathrm{~ms}$ ( depol $_{20 \mathrm{~ms}}$ ) or the first $2 \mathrm{~s}$ of $C_{\mathrm{m}}$ decay following depol ${ }_{20 \mathrm{~ms} \times 10}$ (Wu et al., 2009). To determine the efficiency of endocytosis, we also measured $\Delta C \mathrm{~m}_{25 \mathrm{~s}}$ or $\Delta C \mathrm{~m}_{45 \mathrm{~s}}$, which was the difference between the $C_{\mathrm{m}}$ baseline and the $C_{\mathrm{m}}$ value at 25 or $45 \mathrm{~s}$ after termination of depol ${ }_{20 \mathrm{~ms}}$ or $\mathrm{depol}_{20 \mathrm{~ms} \times 10}$. Time constant $(\tau)$ is provided in describing endocytosis kinetics in the control, but not in judging drug effects, because cases with extremely sluggish $C_{\mathrm{m}}$ decay weighed heavily in comparing $\tau$ between groups (Wu et al., 2009). Data are presented as mean \pm SEM. The statistical test was Student's unpaired $t$ test, with $p<0.05$ indicating a significant difference.

\section{Results \\ MLCKip impairs slow endocytosis}

Endocytosis at the calyx depends on activity, with mild stimulation triggering slow clathrin-dependent, dynamin-dependent endocytosis and strong stimulation inducing an additional rapid form of endocytosis that depends on dynamin but probably not clathrin (Wu et al., 2005, 2009; Yamashita et al., 2005; Xu et al., 2008; Hosoi et al., 2009). $\mathrm{Ca}^{2+} /$ calmodulin has been found to regulate both forms of endocytosis in immature calyces (Wu et al., 2009; Yamashita et al., 2010). Thus, we first investigated whether MLCK is involved in the classical slow endocytosis. We established the standard whole-cell patch-clamp configuration on the calyx terminals from 7 - to 10 -d-old rats, and monitored changes in $C_{\mathrm{m}}$ induced by membrane depolarization. At control calyces, a train of action potential-equivalent pulses (20 depolarization steps from -80 to $0 \mathrm{mV}$ for $1 \mathrm{~ms}$ delivered every $9 \mathrm{~ms}$, referred to as APeT below; $\mathrm{Xu}$ and $\mathrm{Wu}, 2005$; Yamashita et al., $2005)$ triggered an abrupt $C_{\mathrm{m}}$ jump $\left(\Delta C_{\mathrm{m}}\right)$ of $322 \pm 26 \mathrm{fF}(n=$ 10 ), followed by monoexponential $C_{\mathrm{m}}$ decay with a $\tau$ of $14.7 \pm$ $2.1 \mathrm{~s}$ toward the prestimulus level (Fig. $1 A i, B$ ). Because $C_{\mathrm{m}}$ is proportional to the surface area of the terminals, $\Delta C_{\mathrm{m}}$ reflects exocytosis and correlates well with cumulative EPSCs, whereas $C_{\mathrm{m}}$ decay reflects endocytosis of membrane (Sun and $\mathrm{Wu}, 2001$; Wu et al., 2005). The initial rate of $C_{\mathrm{m}}$ decay, Rate_endo, was $23 \pm 1.8 \mathrm{fF} / \mathrm{s}$ in control (Fig. $1 A, B$ ). The net $C_{\mathrm{m}}$ increase at $25 \mathrm{~s}$ after the stimulation $\left(\Delta C \mathrm{~m}_{25 \mathrm{~s}}\right)$ was $56 \pm 17 \mathrm{fF}$, reflecting nearly full recovery of the amount of exocytosed membrane. When the pipette solution contained $2 \mu \mathrm{M}$ MLCKip, a water-soluble highly selective inhibitor of MLCK (Lukas et al., 1999), $\Delta C_{\mathrm{m}}$ slightly increased ( $366 \pm 40 \mathrm{fF}, n=10, p=0.37$ ) while the following $C_{\mathrm{m}}$ decay became slower, resulting in a lower Rate_endo $(9.2 \pm 2.3$ $\mathrm{fF} / \mathrm{s}, p<0.01)$ and more $\Delta \mathrm{Cm}_{25 \mathrm{~s}}(185 \pm 34 \mathrm{fF}, p<0.01$; Fig. $1 A i, B)$. To provide a positive control, we tested effects of DYNip, which has been shown to impair slow endocytosis at calyces (Hosoi et al., 2009) by interfering with dynamin functions. Consistent with the previous study, DYNip $(100 \mu \mathrm{M})$ reduced Rate_endo $(9.9 \pm 3.6 \mathrm{fF} / \mathrm{s}, n=6, p<0.01)$ and raised $\Delta \mathrm{Cm}_{25 \mathrm{~s}}$ $(144 \pm 22 \mathrm{fF}, p<0.01)$. The similar effects of MLCKip and DYNip indicate that MLCKip is an effective inhibitor of the slow endocytosis induced by APeT.

We continued to evaluate effects of MLCKip on slow endocytosis induced by a prolonged depolarization pulse, which is a widely used paradigm in the field (Wu et al., 2005; Renden and von Gersdorff, 2007; Hosoi et al., 2009; Sun et al., 2010; Yamashita et al., 2010). Consistent with previous studies, a depolarization pulse from -80 to $0 \mathrm{mV}$ for $20 \mathrm{~ms}$ (referred to as depol $\left._{20 \mathrm{~ms}}\right)$ triggered $\Delta C_{\mathrm{m}}$ of $437 \pm 45 \mathrm{fF}$ in control $(n=10)$ and the following $C_{\mathrm{m}}$ decay, which was fit with a monoexponential $\tau$ of $16.6 \pm 1.6 \mathrm{~s}$ and an initial linear Rate_endo of $29.5 \pm 4.0 \mathrm{fF} / \mathrm{s}$ (Fig. $1 A i i, B)$. MLCKip did not change $\Delta \bar{C}_{\mathrm{m}}(450 \pm 35 \mathrm{fF}, n=10$, $p=0.82)$, but prolonged $C_{\mathrm{m}}$ decay, leading to decreased Rate_endo $(14.8 \pm 2.8 \mathrm{fF} / \mathrm{s}, p<0.01)$ and increased $\Delta C \mathrm{~m}_{25 \mathrm{~s}}(165 \pm$ $18 \mathrm{fF}$ vs $75 \pm 21 \mathrm{fF}$ in control, $p<0.01)$. DYNip similarly slowed down the $C_{\mathrm{m}}$ decay following depol ${ }_{20 \mathrm{~ms}}$ (Rate_endo, $11.8 \pm 2.9$ $\mathrm{fF} / \mathrm{s} ; \Delta \mathrm{Cm}_{25}, 230 \pm 30 \mathrm{fF} ; n=8, p<0.01$ vs control; Fig. 1$)$. 

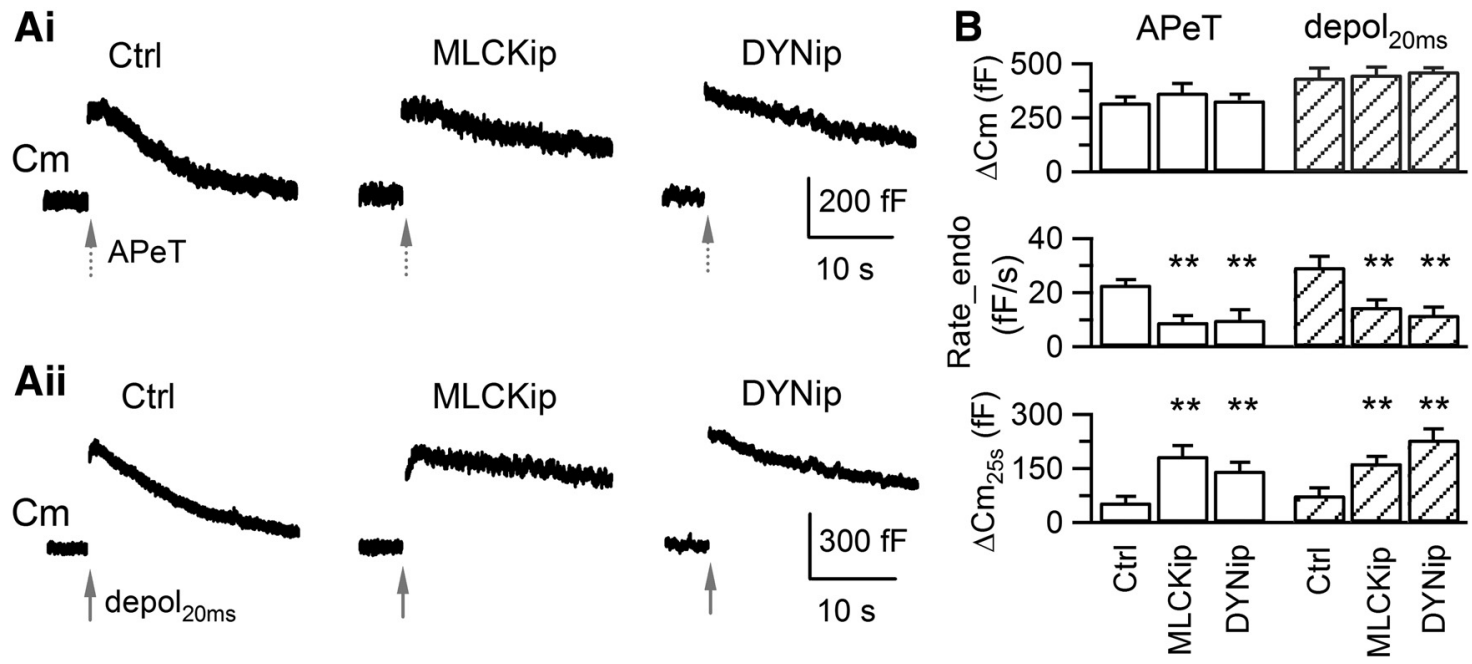

Figure 1. MLCKip impairs slow endocytosis at the calyx. $A$, Sampled $C_{m}$ recordings showing exocytosis and endocytosis induced by $A P e T$ ( $A$ i $)$ and depol ${ }_{20 \mathrm{~ms}}(\boldsymbol{A i i})$. The calyx terminals were dialyzed with the control pipette solution (Ctrl) or with the solution including MLCKip $(2 \mu \mathrm{M})$, or DYNip $(100 \mu \mathrm{M}) . \boldsymbol{B}, \Delta C_{\mathrm{m}}$, Rate_endo, and $\Delta \mathrm{Cm}_{25 \mathrm{~s}}$ induced by APeT from control ( $\left.n=10\right)$, MLCKip $(n=10)$, and DYNip $(n=6)$, and induced by depol $20 \mathrm{~ms}$ from control $(n=10)$, MLCKip $(n=10)$, and DYNip $(n=8) .{ }^{* *} p<0.01$.

Together, the results show that MLCKip can inhibit slow endocytosis induced by either APeT or depol $20 \mathrm{~ms}$ at calyces.

Our conclusion regarding inhibition of MLCKip on slow endocytosis is based on comparison of the kinetics of $C_{\mathrm{m}}$ decay following APeT and depol $20 \mathrm{~ms}$. At the calyx, inhibition of MLCK induces mixed changes in synaptic transmission, including an increase in the number of fast-releasing vesicles as well as the frequency of miniature EPSCs (mEPSCs) at rest (Srinivasan et al., 2008). Also, compound fusion of vesicles is found following depolarization, leading to insertion of larger vesicle membrane into the plasma membrane during exocytosis (He et al., 2009; Xue and $\mathrm{Wu}, 2010$ ). If inhibition of MLCK selectively promotes these changes during the asynchronous release immediately after depolarization, fusion of more and/or larger vesicles would slow down the initial $C_{\mathrm{m}}$ decay and confound our analysis of endocytosis kinetics. To address this concern, we studied effects of presynaptic dialysis of MLCKip on mEPSC by performing simultaneous patch-clamp recordings on both the calyx terminal and the postsynaptic principal neuron ( $\mathrm{Xu}$ and $\mathrm{Wu}, 2005)$. The bath solution contained $100 \mu \mathrm{M}$ cyclothiazide, which ensures accurate detection of asynchronous glutamate release after stimulation by blocking AMPA receptor desensitization. At control synapses $(n=6)$, the mEPSC frequency was $3.8 \pm 0.8 \mathrm{~Hz}$ at rest and $10.3 \pm$ $2.9 \mathrm{~Hz}(p=0.06)$ within $4 \mathrm{~s}$ after APeT (Fig. $2 A, C)$. At synapses with presynaptic dialysis of MLCKip $(n=7)$, the mEPSC frequency was $5.5 \pm 1 \mathrm{~Hz}$ at rest and increased to $15 \pm 3.2 \mathrm{~Hz}(p=$ 0.02 ) after APeT (Fig. $2 B, C$ ). In experiments in which APeT was replaced with depol $20 \mathrm{~ms}$ (Fig. $2 D-F$ ), the mEPSC frequency in control increased from $4.9 \pm 1.2 \mathrm{~Hz}$ at rest to $12 \pm 2.4 \mathrm{~Hz}(n=6$, $p=0.02$ ) within $4 \mathrm{~s}$ after $\operatorname{depol}_{20 \mathrm{~ms}}$, and in MLCKip from $5.2 \pm$ $1.5 \mathrm{~Hz}$ at rest to $13.6 \pm 3.8 \mathrm{~Hz}$ after $\operatorname{depol}_{20 \mathrm{~ms}}(n=7, p=0.08)$. Compared with control, MLCKip does not induce more fusion events before and after APeT or $\operatorname{depol}_{20 \mathrm{~ms}}(p=0.23-0.76)$. We did not observe any unusual increase of mEPSC size in MLCKip either. The mean amplitude of mEPSCs over the first $4 \mathrm{~s}$ after stimulation fell within $28.2-30.6 \mathrm{pA}$ in different conditions, showing no obvious effect of APeT, $\operatorname{depol}_{20 \mathrm{~ms}}$, or MLCKip ( $p=$ $0.77-0.96,6$ control synapses and 7 MLCKip synapses; Fig. $2 C, F)$. In summary, MLCKip does not affect either the number or the size of exocytosed vesicles following mild depolarization. Therefore, MLCKip slows down $C_{\mathrm{m}}$ decay following APeT or depol $_{20 \mathrm{~ms}}$ by blocking endocytosis, not by modifying vesicle release after the stimulation.

\section{Inhibitors of MLCK/myosin impair slow endocytosis}

The inhibitory effects of MLCKip on slow $C_{\mathrm{m}}$ decay suggest that MLCK accelerates slow endocytosis. To verify this conclusion, we examined whether the slow endocytosis induced by depol ${ }_{20 \mathrm{~ms}}$ is affected by ML-7 and wortmannin, which are two additional inhibitors of MLCK widely used in studying neuronal functions (Polo-Parada et al., 2005; Tokuoka and Goda, 2006; Lee et al., 2008, 2010; Srinivasan et al., 2008). ML-7 competes with ATP for binding with MLCK (Saitoh et al., 1987), and wortmannin targets at or near the catalytic site of MLCK at a concentration $\geq 1 \mu \mathrm{M}$ (Nakanishi et al., 1992). Because the final solutions of the blockers contained $0.1 \%$ DMSO, we used $0.1 \%$ DMSO in the pipette solution as their control. Consistent with previous studies (Xu et al., 2008; Wu et al., 2009; Yamashita et al., 2010), DMSO did not influence either exocytosis or endocytosis following depol $_{20 \mathrm{~ms}}$ (Fig. $3 A, B$ ). Specifically, $\Delta C_{\mathrm{m}}$ reflecting exocytosis was $442 \pm 36$ $\mathrm{fF}(n=10, p=0.93)$, Rate_endo was $29.7 \pm 3.2 \mathrm{fF} / \mathrm{s}(p=0.96)$, and $\Delta C \mathrm{~m}_{25 \mathrm{~s}}$ was $73 \pm 22 \mathrm{fF}(p=0.94$; Fig. $3 A, B)$. By contrast, including ML-7 $(20 \mu \mathrm{M})$ in the pipette solution significantly prolonged $C_{\mathrm{m}}$ decay, resulting in decreased Rate_endo (12.6 \pm 1.9 $\mathrm{fF} / \mathrm{s}, n=10, p<0.01)$ and increased $\Delta \mathrm{Cm}_{25 \mathrm{~s}}(214 \pm 22 \mathrm{fF}, p<$ $0.01)$. Dialysis with wortmannin $(10 \mu \mathrm{M})$ also reduced Rate_endo $(7.9 \pm 1.4 \mathrm{fF} / \mathrm{s}, n=8, p<0.01)$ and increased $\Delta C \mathrm{~m}_{25 \mathrm{~s}}(260 \pm 58$ $\mathrm{fF}, p<0.01$; Fig. $3 A, B)$. Thus, all three MLCK blockers, MLCKip, ML-7, and wortmannin, consistently inhibited slow endocytosis.

Activation of MLCK can phosphorylate the light chain of myosin. To determine whether myosin acts together with MLCK in regulating slow endocytosis, we examined effects of dialysis with blebbistatin, which selectively blocks the ATPase activity of myosin II (Kovacs et al., 2004) and has been shown to inhibit refilling of fast-releasing vesicles after tetanic stimulation at the calyx (Lee et al., 2008, 2010). Blebbistatin $(100 \mu \mathrm{M})$ decreased Rate_endo after $\mathrm{depol}_{20 \mathrm{~ms}}$ to $9.3 \pm 3.1 \mathrm{fF} / \mathrm{s}(n=10, p<0.01)$ and increased $\Delta C \mathrm{~m}_{25 \mathrm{~s}}$ to $228 \pm 32 \mathrm{fF}(p<0.01$; Fig. $3 A, B)$, suggesting that myosin II is involved in slow endocytosis. Based on the effects of three MLCK inhibitors (MLCKip, ML-7, and wortmannin) and a myosin II inhibitor (blebbistatin) on slow endocytosis, we conclude that MLCK activity facilitates the classical slow endocytosis. 

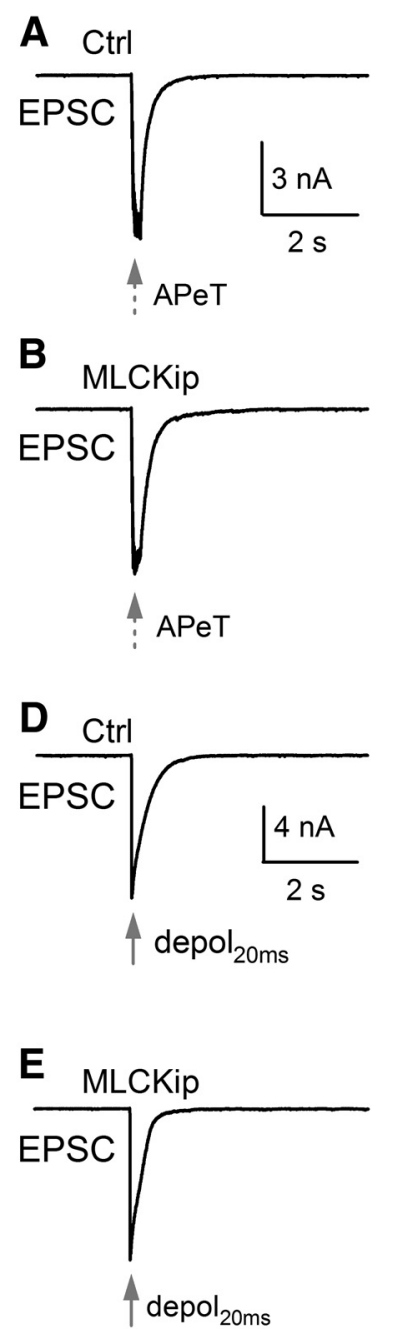
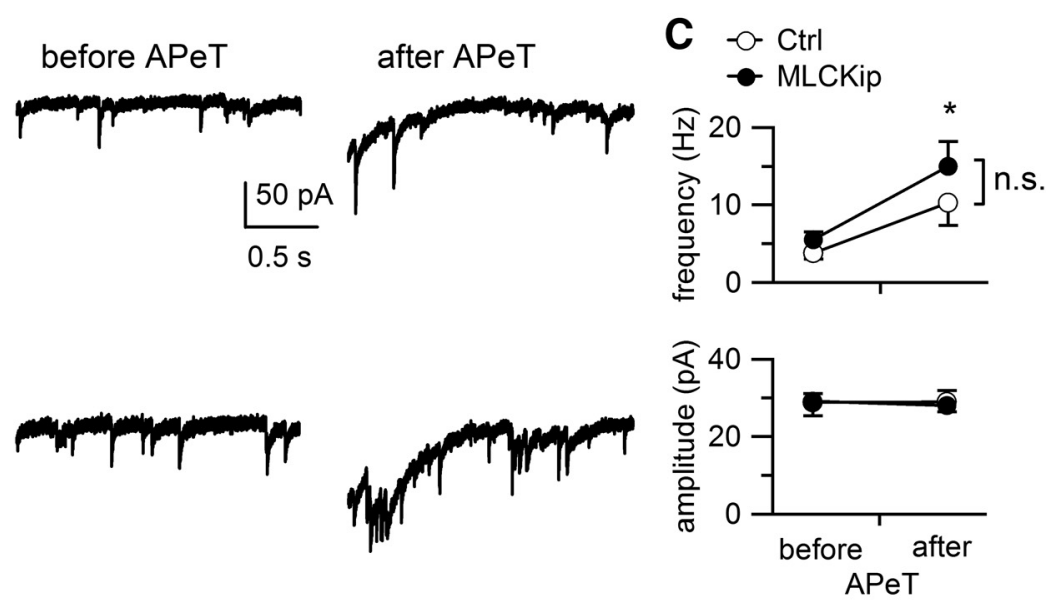

$\mathrm{APeT}$
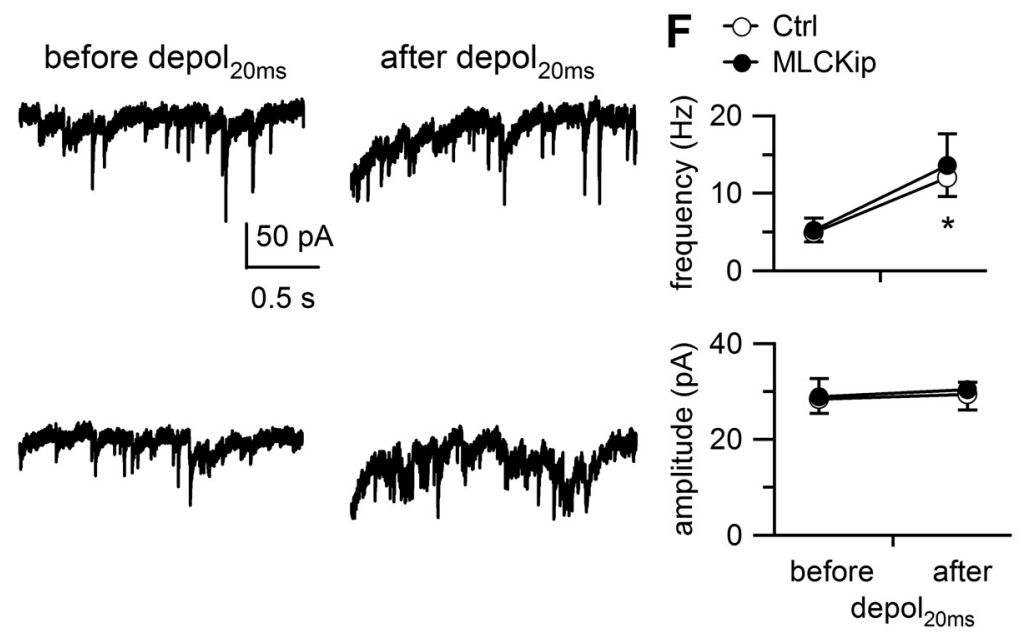

Figure 2. MLCKip does not alter asynchronous release following mild stimulation. $A$, Sampled postsynaptic recordings from a control synapse under stimulation with APeT. The right two traces were expanded to show mEPSC events before and after APeT. $B$, Sampled postsynaptic recordings from a synapse with presynaptic dialysis of MLCKip ( $2 \mu \mathrm{m}$ ). Scales and arrangement of traces are identical with those in $\boldsymbol{A}$. C, Frequency and amplitude of mEPSCs before and after APeT, which are mean and SEM of the averages in control $(n=6)$ and MLCKip synapses ( $n=7)$. $\boldsymbol{D}$, Sampled postsynaptic recordings from a control synapse under stimulation with depol ${ }_{20 \mathrm{~ms}}$. The right two traces were expanded to show mEPSC events before and after depol ${ }_{20 \mathrm{~ms}} \boldsymbol{E}_{\text {, }}$ Sampled postsynaptic recordings from a synapse with presynaptic dialysis of MLCKip. Scales and arrangement of traces are identical with those in $\boldsymbol{D}$. $\boldsymbol{F}$, Frequency and amplitude of mEPSCs before and after depol $20 \mathrm{~ms}$ in control $(n=6)$ and MLCKip $(n=7)$. Note that stimulation with APeT or depol $20 \mathrm{~ms}$ significantly increases the mEPSC frequency $\left({ }^{*} p<0.05\right.$ when applicable). The mEPSC frequency in MLCKip is not significantly different (n.s.) from that in control.

None of the blockers affected $\Delta C_{\mathrm{m}}$ (Figs. $1 B, 3 B$ ), ruling out the possibility that their inhibition of slow endocytosis results from modulation of exocytosis.

\section{MLCKip slows down the rapid endocytosis following intense stimulation}

Having shown that MLCK accelerates slow endocytosis, we next investigated whether MLCK modulates a rapid form of endocytosis induced by intense activity (Wu et al., 2005). In control, a 10 $\mathrm{Hz}$ train of ten $20 \mathrm{~ms}$ depolarization pulses from -80 to $0 \mathrm{mV}$ (referred to as depol $\left.{ }_{20 \mathrm{~ms} \times 10}\right)$ evoked a $\Delta C_{\mathrm{m}}$ of $1266 \pm 105 \mathrm{fF}(n=$ $10)$ and a biexponential $C_{\mathrm{m}}$ decay with a rapid $\tau$ of $2.4 \pm 0.4 \mathrm{~s}$ (median $=2.1 \mathrm{~s}, 34.1 \pm 4.8 \%$ of the total amount) and a slow $\tau$ of $20.6 \pm 2.1 \mathrm{~s}$ (median $=18.2 \mathrm{~s}$; Fig. $4 A, C)$. The Rate_endo measured within $2 \mathrm{~s}$ of $C_{\mathrm{m}}$ decay after depol $_{20 \mathrm{~ms} \times 10}$ was $177 \pm 15 \mathrm{fF} / \mathrm{s}$, reflecting the rate of membrane retrieval primarily through the rapid mechanism (Wu et al., 2005, 2009; Xu et al., 2013). Introducing MLCKip into the terminals decreased Rate_endo to $113 \pm 24 \mathrm{fF} / \mathrm{s}(n=10, p=0.03$; Fig. $4 A, B)$, and prolonged both rapid and slow $\tau$ (median $=4.0 \mathrm{~s}$ and $54.1 \mathrm{~s}$, respectively) without changing the contribution from rapid endocytosis (33.5 \pm $5.5 \%)$, which resulted in larger $\Delta C \mathrm{~m}_{45 \mathrm{~s}}(332 \pm 56 \mathrm{fF}, p<0.01)$ than that in control $(101 \pm 22 \mathrm{fF})$. Because rapid endocytosis is inhibited by dynamin blockers (Xu et al., 2008), we used the dynamin inhibitor, DYNip, as a positive control. DYNip decreased Rate_endo $(106 \pm 10 \mathrm{fF} / \mathrm{s}, n=6, p<0.01)$ and increased $\Delta C \mathrm{~m}_{45 \mathrm{~s}}(315 \pm 46 \mathrm{fF}, p<0.01)$ to an extent similar to that of MLCKip (Fig. 4). Like other specific inhibitors of dynamin (Xu et al., 2008), DYNip increased both rapid and slow $\tau$ (median $=$ $4.6 \mathrm{~s}$ and $66.5 \mathrm{~s}$, respectively) without altering the contribution of rapid endocytosis $(42.3 \pm 5.8 \%, p=0.31)$. These results indicate that MLCKip effectively inhibits the rapid $C_{\mathrm{m}}$ decay induced by $\operatorname{depol}_{20 \mathrm{~ms} \times 10}$.

To determine whether MLCKip slows down rapid $C_{\mathrm{m}}$ decay by promoting asynchronous vesicle fusion or the size of fused vesicles after depol $_{20 \mathrm{~ms} \times 10}$, we measured mEPSCs from the postsynaptic neurons innervated by the calyx terminals under dialysis with MLCKip or control pipette solution. In control synapses 


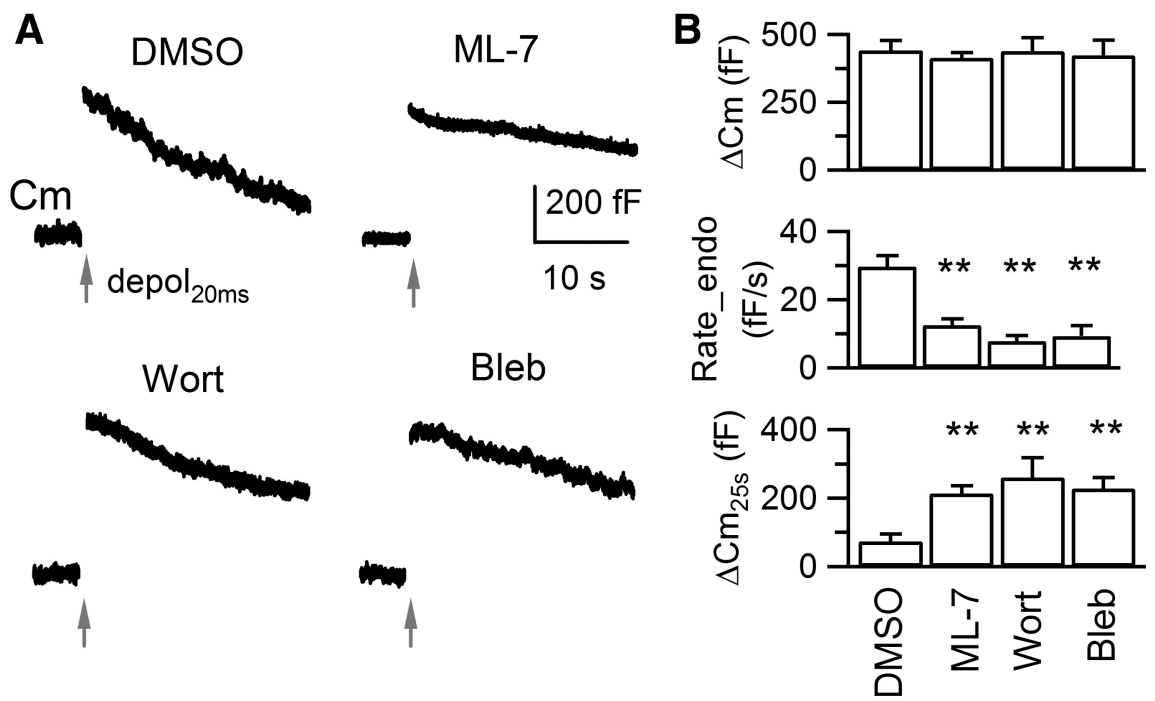

Figure 3. ML-7, wortmannin, and blebbistatin inhibit slow endocytosis. $A$, Sampled membrane capacitance $\left(C_{m}\right)$ recordings showing exocytosis and endocytosis induced by depo ${ }_{20 \mathrm{~ms}}$ from the calyx terminals dialyzed with pipette solution containing either DMSO (0.1\%), ML-7 (20 $\mu \mathrm{M})$, wortmannin (Wort, $10 \mu \mathrm{M})$, or blebbistatin (Bleb, $100 \mu \mathrm{M}) . B, \Delta C_{\mathrm{m}}$, Rate_endo and $\Delta \mathrm{Cm}_{25 \mathrm{~s}}$ induced by depol 20 ms from DMSO $(n=10), \operatorname{ML}-7(n=10)$, wortmannin $(n=8)$ and blebbistatin $(n=10) .{ }^{* *} p<0.01$.

the amplitude or frequency elevation in mEPSC events (Fig. $5 B, C$ ). Therefore, MLCKip slows down the rapid $C_{\mathrm{m}}$ decay after depol $_{20 \mathrm{~ms} \times 10}$ by inhibition of rapid membrane retrieval, not by facilitation of asynchronous vesicle fusion.

\section{Inhibitors of MLCK/myosin slow down rapid endocytosis}

To verify the involvement of MLCK in rapid endocytosis, we further examined effects of ML-7, wortmannin, and blebbistatin (Fig. 6). In calyces dialyzed with DMSO (0.1\%), depol $20 \mathrm{~ms} \times 10$ induced both rapid and slow components which were similar to control, with a Rate_endo of $185.9 \pm 25.4 \mathrm{fF} / \mathrm{s}(n=10, p=0.78)$ and $\Delta C \mathrm{~m}_{45 \mathrm{~s}}$ of $143 \pm 33 \mathrm{fF}(p=0.31)$. ML-7 $(20 \mu \mathrm{M})$ reduced Rate_endo to $112.6 \pm$ $13.5 \mathrm{fF} / \mathrm{s}(n=10, p=0.02)$ and increased $\Delta C \mathrm{~m}_{45 \mathrm{~s}}$ of $335 \pm 73 \mathrm{fF}(p=0.03)$. Similar effects were observed for wortmannin (10 $\mu \mathrm{M})$ and blebbistatin (100 $\mu \mathrm{M}$; Fig. $6 A, B)$. As determined by the biexponential fit-
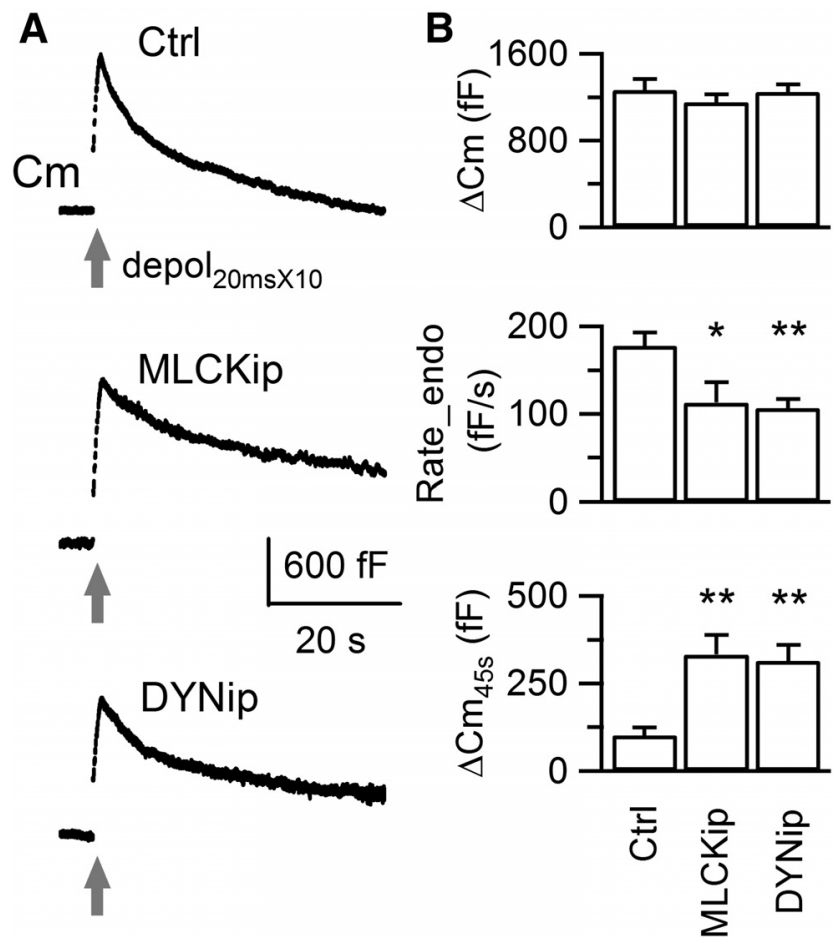

Figure 4. MLCKip slows down rapid endocytosis following intense stimulation. $\boldsymbol{A}$, Sampled $C_{m}$ recordings showing exocytosis and endocytosis induced by depol ${ }_{10 \times 20 \mathrm{~ms}}$ from calyces dialyzed with the control, MLCKip (2 $\mu \mathrm{M})$, or DYNip $(100 \mu \mathrm{m})$ solution. $\boldsymbol{B}, \Delta C_{\mathrm{m}}$, Rate_endo and $\Delta \mathrm{Cm}_{55}$ induced by depol ${ }_{10 \times 20 \mathrm{~ms}}$ from control $(n=10), \operatorname{MLCKip}(n=10)$, and DYNip $(n=6)$. ${ }^{*} p<0.05,{ }^{* *} p<0.01$.

$(n=6)$, the mEPSC frequency increased from $4.4 \pm 0.7 \mathrm{~Hz}$ at rest to $31.4 \pm 2 \mathrm{~Hz}(p<0.01)$ during $3 \mathrm{~s}$ after $\operatorname{depol}_{20 \mathrm{~ms} \times 10}$. The averaged mEPSC amplitude increased from $26 \pm 1.5 \mathrm{pA}$ to $29.6 \pm 2.1 \mathrm{pA}(p=0.17)$ after the stimulation (Fig. $5 A, C)$, which agrees with an increasing trend of mEPSC size after prolonged repetitive depolarization ( $\mathrm{He}$ et al., 2009; Xue and $\mathrm{Wu}, 2010$; Fioravante et al., 2011). MLCKip did not further increase ting of $C_{\mathrm{m}}$ decay, ML-7, wortmannin, and blebbistatin all increased rapid $\tau$ (median $=3.6,3.4$, and $3.7 \mathrm{~s}$, respectively, vs $2.0 \mathrm{~s}$ in DMSO) and slow $\tau$ (median $=53.8,69.5$, and $50.0 \mathrm{~s}$, respectively, vs $26.3 \mathrm{~s}$ in DMSO) without changing their proportions (rapid component: $34.4 \pm 4.1 \%$, $37.6 \pm 8.7 \%$, and $30.5 \pm 3.9 \%$, respectively, vs $34.2 \pm 3.9 \%$ in DMSO). Therefore, the four blockers of MLCK/myosin decreased not only the rate of slow endocytosis induced by APeT or $\operatorname{depol}_{20 \mathrm{~ms}}$ but also the rate of rapid membrane retrieval following $\operatorname{depol}_{20 \mathrm{~ms} \times 10}$. Meanwhile, $\Delta C_{\mathrm{m}}$ following depol $_{20 \mathrm{~ms} \times 10}$ was slightly smaller in MLCK/myosin blockers, which is probably caused by slower clearance of fused membrane from active zones due to impairment of rapid endocytosis (Hosoi et al., 2009; Wu et al., 2009; Hua et al., 2013). The mild reduction of $\Delta C_{\mathrm{m}}$ should not underlie the impairment of endocytosis.

\section{MLCK/myosin functions downstream of $\mathrm{Ca}^{2+}$ influx}

At the calyx, the kinetics of endocytosis induced by membrane depolarization depends on $\mathrm{Ca}^{2+}$ entry via voltage-gated $\mathrm{Ca}^{2+}$ channels (Xue et al., 2012). Among the inhibitors we used, ML-7 has been found to reduce $\mathrm{Ca}^{2+}$ channel current in cultured hippocampal neurons (Tokuoka and Goda, 2006). To exclude interference of possible reduction of $\mathrm{Ca}^{2+}$ entry in our experimental conditions, we measured $\mathrm{Ca}^{2+}$ influx induced by depol ${ }_{20 \mathrm{~ms}}$ and $\operatorname{depol}_{20 \mathrm{~ms} \times 10}$. In control, depol ${ }_{20 \mathrm{~ms}}$ induced $\mathrm{Ca}^{2+}$ current with a peak amplitude $\left(I \mathrm{Ca}_{\text {peak }}\right)$ of $2.0 \pm 0.2 \mathrm{nA}(n=10)$ and a current charge $\left(Q_{\mathrm{Ca}}\right)$ of $32.9 \pm 2.5 \mathrm{pC}$ (Fig. $7 B$ ). For the treatments of DMSO and blockers of MLCK/myosin, $I \mathrm{Ca}_{\text {peak }}$ fell between 2 and $2.1 \mathrm{nA}$ and $Q_{\mathrm{Ca}}$ between 32.3 and $35.5 \mathrm{pC}$, showing no difference from control ( $p=0.77-0.93$ and $0.82-0.92$, respectively). Depol $_{20 \mathrm{~ms} \times 10}$, which repeats depol $_{20 \mathrm{~ms}}$ for 10 times at an interval of $80 \mathrm{~ms}$, induced a total $Q_{\mathrm{Ca}}$ of $227.2 \pm 19.2 \mathrm{pC}(n=10)$ in control (Fig. 7D). Depol $20 \mathrm{~ms} \times 10$ evoked similar total $Q_{\mathrm{Ca}}$ in DMSO and the blockers $\left(Q_{\mathrm{Ca}}=212.4-246.1 \mathrm{pC}, n=8-10, p=\right.$ 0.26-0.92). MLCKip, ML-7, wortmannin, and blebbistatin did not change $I_{\mathrm{Ca}}$ (channel current) or $Q_{\mathrm{Ca}}$ under $\operatorname{depol}_{20 \mathrm{~ms}}$ and depol $_{20 \mathrm{~ms} \times 10}$, which is consistent with a previous study using brief depolarization pulses (Srinivasan et al., 2008). Therefore, 


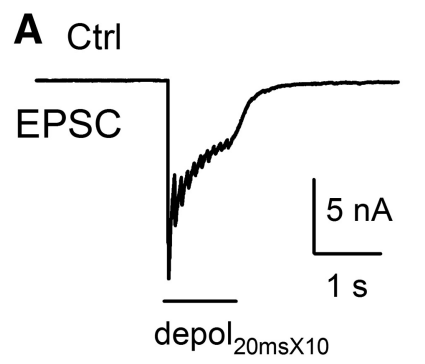

B

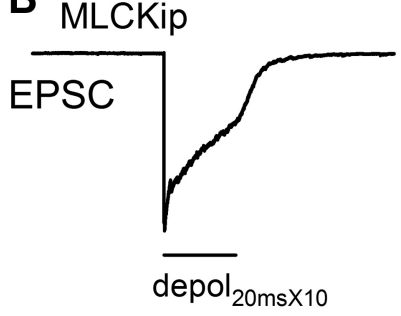

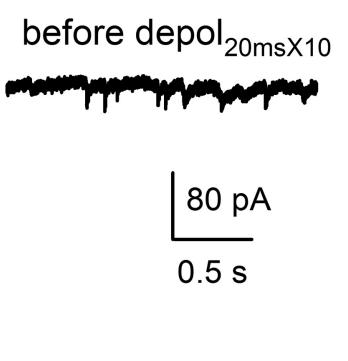
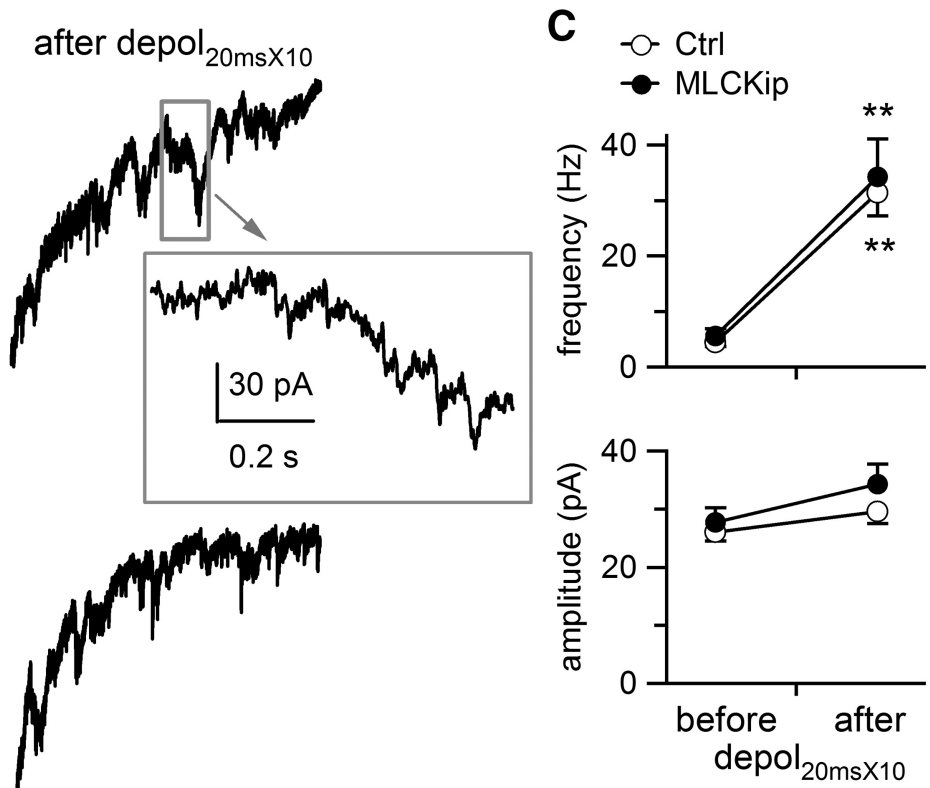

Figure 5. MLCKip does not alter asynchronous release following intense stimulation. $\boldsymbol{A}$, Sampled postsynaptic recordings from a control synapse under stimulation with depol $20 \mathrm{~ms} \times 10$. The right two traces were expanded to show mEPSC events before and after the stimulation. As shown in the inset, large grooves in postsynaptic currents are composed of multiple narrowly separated mEPSC events, which appear more frequently after depol ${ }_{20 \mathrm{~ms} \times 10}$. $\boldsymbol{B}$, Sampled postsynaptic recordings from a synapse with presynaptic dialysis of MLCKip ( $\left.2 \mu \mathrm{m}\right)$. Scales and arrangement of traces are identical with those in $A$. C, Frequency and amplitude of $\mathrm{mEPSC}$ before and after depol $\mathrm{I}_{20 \mathrm{~ms} \times 10}$. The $\mathrm{mEPSC}$ frequency drastically increases after depol ${ }_{20 \mathrm{~ms} \times 10}\left({ }^{* *} p<0.01\right)$ in both control $(n=6)$ and MLCKip ( $n=6)$, while the amplitude increases less significantly. MLCKip does not induce further changes.

the inhibitors of MLCK/myosin II impair slow and rapid endocytosis by acting downstream of $\mathrm{Ca}^{2+}$ influx.

\section{Simultaneous inhibition of MLCK and calmodulin does not induce synergistic} inhibition of endocytosis

Downstream of $\mathrm{Ca}^{2+}$ influx, calmodulin has been shown to regulate endocytosis in the calyx of Held and hippocampal boutons (Wu et al., 2009; Sun et al., 2010; Yamashita et al., 2010; Yao and Sakaba, 2012). To test whether MLCK and calmodulin regulate endocytosis along the same pathway, we investigated whether combining a calmodulin inhibitor, CBD, and MLCKip could produce synergistic inhibition of endocytosis. Consistent with the previous studies (Wu et al., 2009; Yamashita et al., 2010), CBD at $500 \mu \mathrm{M}$ significantly inhibited both slow and rapid endocytosis (Fig. 8). Specifically, CBD reduced Rate_endo following depol ${ }_{20 \mathrm{~ms}}$ to $10.2 \pm 2.8 \mathrm{fF} / \mathrm{s}(n=8, p<0.01$ vs control in Fig. 1) and increased $\Delta \mathrm{Cm}_{25 \mathrm{~s}}$ to $268 \pm 35 \mathrm{fF}(p<0.01$; Fig. 8). CBD increased $\Delta C \mathrm{~m}_{25 \mathrm{~s}}$ more than MLCKip (165 $\pm 18 \mathrm{fF}$ in Fig. $1, p=0.01)$, but decreased Rate_endo to a similar extent $(p=0.26)$, showing mildly stronger inhibition of endocytosis. Combining CBD and MLCKip in the pipette solution resulted in a Rate_endo of $8.4 \pm$ $2.2 \mathrm{fF} / \mathrm{s}\left(n=8, p<0.01\right.$ vs control) and a $\Delta C_{25 \mathrm{~s}}$ of $295 \pm 47 \mathrm{fF}$ $(p<0.01)$. The changes are similar to those in CBD alone $(p=0.64$ and 0.66 , respectively). Combining CBD and MLCKip thus does not generate synergistic effects on slow endocytosis.

Similar comparison was done on rapid endocytosis (Fig. 8C,D). CBD decreased the rapid Rate_endo following depol $_{20 \mathrm{~ms} \times 10}$ to
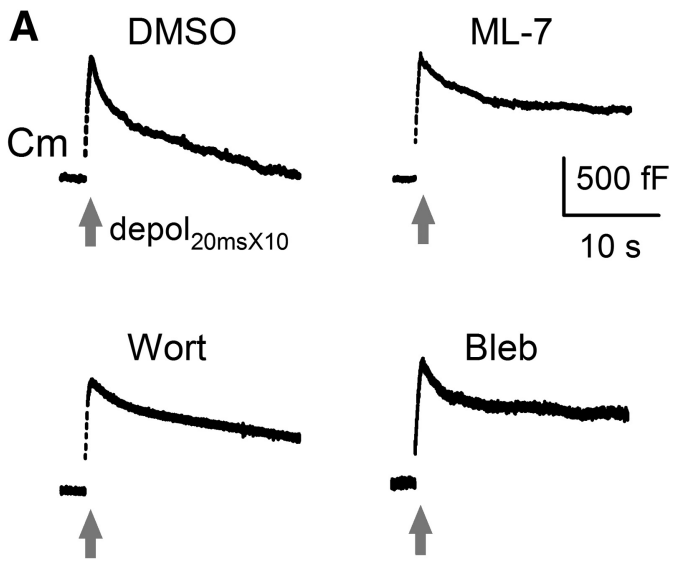

Figure 6. ML-7, wortmannin, and blebbistatin slow down rapid endocytosis following intense stimulation. $\boldsymbol{A}$, Sampled $C_{\mathrm{m}}$ recordings showing exocytosis and endocytosis induced by depo $\mathrm{I}_{20 \mathrm{~ms} \times 10}$ from calyces dialyzed with DMSO (0.1\%), ML-7 (20 $\left.\mu \mathrm{M}\right)$, wortmannin $(10 \mu \mathrm{m})$, or blebbistatin $(100 \mu \mathrm{M}) . B, \Delta C_{\mathrm{m}}$, Rate_endo and $\Delta \mathrm{Cm}_{45 \mathrm{~s}}$ induced by depol ${ }_{20 \mathrm{~ms} \times 10}$ from DMSO $(n=10)$, ML-7 $(n=10)$, wortmannin $(n=8)$, and blebbistatin $(n=10)$.

$80.1 \pm 11.2 \mathrm{fF} / \mathrm{s}(n=7, p<0.01$ vs control $)$, and raised $\Delta C \mathrm{~m}_{45 \mathrm{~s}}$ to $342 \pm 60 \mathrm{fF}(p<0.01)$. The effects are indistinguishable from those of MLCKip ( $p=0.29$ and 0.91 , respectively). The combination of CBD and MLCKip reduced Rate_endo to $76.3 \pm$ $14.2 \mathrm{fF} / \mathrm{s}(n=6)$ and increased $\Delta C \mathrm{~m}_{25 \mathrm{~s}}$ to $467 \pm 147 \mathrm{fF}$, which are similar to those in $\mathrm{CBD}$ ( $p=0.83$ and 0.42 , respectively) and MLCKip ( $p=0.28$ and 0.33 , respectively). It is noteworthy that neither individual blockers nor combination of MLCKip and CBD completely abolishes endocytosis, which is seen instead for the rapid $\mathrm{Ca}^{2+}$ chelator, BAPTA (Hosoi et al., 2009; Wu et al., 2009; Yamashita et al., 2010). Thus, although the depolarizationevoked endocytosis in the calyx requires $\mathrm{Ca}^{2+}$, our pharmacolog- 

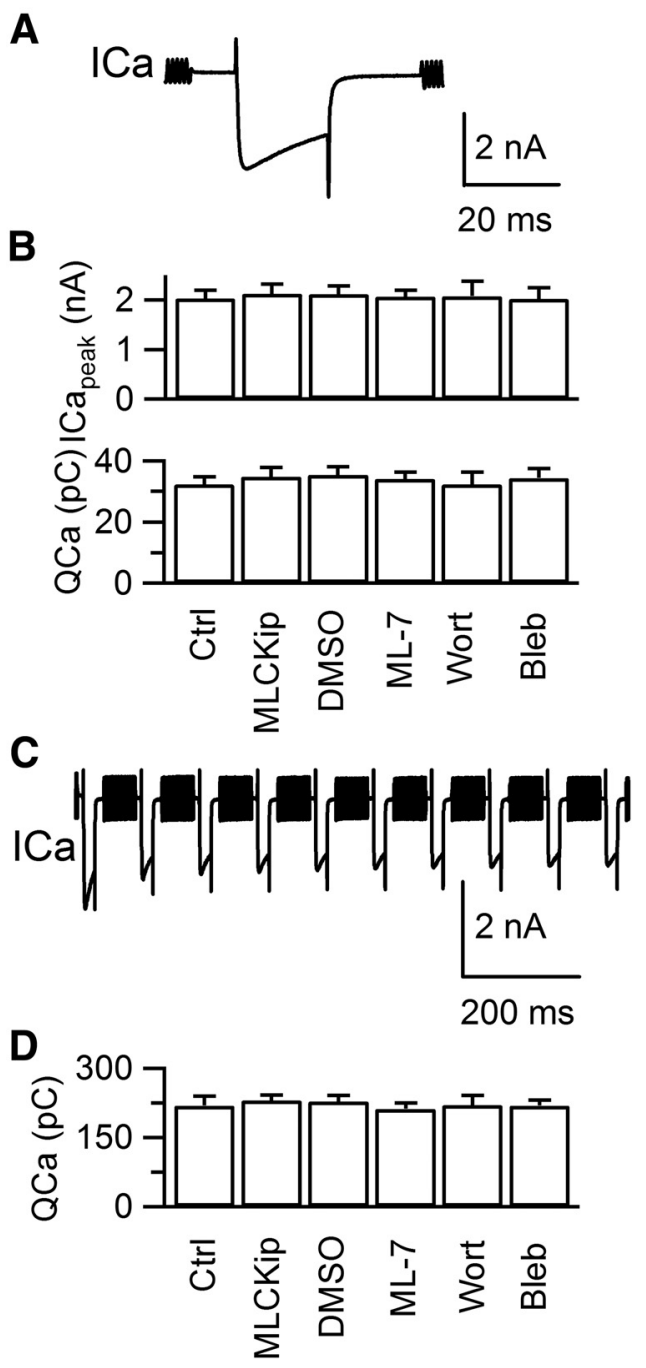

Figure 7. Inhibition of MLCK/myosin II does not affect voltage-gated $\mathrm{Ca}^{2+}$ channel current. $\boldsymbol{A}$, Sampled $\mathrm{Ca}^{2+}$ channel current $\left(I_{\mathrm{Ca}}\right)$ evoked by depol ${ }_{20 \mathrm{~ms}}$ in a control calyx. $\boldsymbol{B}$, Peak amplitude $\left(/ \mathrm{Ca}_{\text {peak }}\right)$ and total charge $\left(Q_{\mathrm{C}_{\mathrm{a}}}\right)$ of $I_{\mathrm{Ca}}$ evoked by depol $\mathrm{I}_{20 \mathrm{~ms}}$ from calyces dialyzed with different pipette solutions (control, $n=10$; MLCKip, $n=10$; DMSO, $n=10$; ML-7, $n=10$; wortmannin, $n=8$; blebbistatin, $n=10)$. C, Sampled $I_{C a}$ evoked by depol ${ }_{20 \mathrm{~ms} \times 10}$ in a control calyx. D, Total charge $\left(Q_{\mathrm{Ca}_{\mathrm{C}}}\right)$ of $I_{\mathrm{Ca}}$ evoked by depol $\mathrm{I}_{20 \mathrm{~ms} \times 10}$ from calyces dialyzed with different pipette solutions (control, $n=10$; MLCKip, $n=10 ; \mathrm{DMS} 0, n=10 ; \mathrm{ML}-7, n=10$; wortmannin, $n=8$; blebbistatin, $n=10$ ).

ical data do not exclude the possible existence of a $\mathrm{Ca}^{2+}$ sensor other than calmodulin (such as synaptotagmin). Nevertheless, combining MLCKip and CBD did not induce synergistic inhibition on slow endocytosis or rapid endocytosis, suggesting that MLCK and calmodulin function through the same pathway to affect endocytosis.

\section{Discussion}

We have observed at the calyx of Held from P7-P10 rats that acutely inhibiting MLCK/myosin with MLCKip, ML-7, wortmannin, and blebbistatin impaired slow endocytosis following APeT and depol $_{20 \mathrm{~ms}}$ (Figs. 1, 3), and rapid endocytosis following $\operatorname{depol}_{20 \mathrm{~ms} \times 10}$ (Figs. 4, 6). We conclude that under both mild and intense activity, MLCK/myosin accelerates endocytosis in this mammalian central synapse.

\section{A role of $\mathrm{MLCK} / \mathrm{myosin}$ in synaptic vesicle endocytosis}

In non-neuronal cells, MLCK/myosin has been reported to regulate different forms of endocytosis, including caveolar endocy- tosis in intestinal epithelia (Schwarz et al., 2007; Marchiando et al., 2010), phagocytosis and pseudopod formation in polymorphonuclear leukocytes (Mansfield et al., 2000), and receptormediated phagocytosis and macropinocytosis in macrophages (Araki et al., 2003). In neurons, a role of MLCK/myosin in endocytosis has remained in doubt. An early study on hippocampal neurons found that inhibition of MLCK/myosin with ML-9 or a nonspecific myosin inhibitor, butanedione monoxime, can attenuate the destaining but not the uptake of FM1-43 (Ryan, 1999). The study suggests that MLCK is not involved in endocytosis under investigation, but does not exclude its participation under different conditions. In the present study, using capacitance measurement to monitor endocytosis with a temporal resolution as high as milliseconds, we found that four blockers of MLCK/myosin all slowed down endocytosis after either mild or intense stimulation, causing impairment similar to or slightly weaker than that of the dynamin inhibitor DYNip (Figs. 1, 3, 4, 6) or the calmodulin inhibitor CBD (Fig. 8), which are recognized potent inhibitors of endocytosis at the calyx (Hosoi et al., 2009; Wu et al., 2009; Yamashita et al., 2010). Our data thus indicate that, like in non-neuronal cells, MLCK/myosin accelerates vesicle endocytosis in the calyx synapse.

Given that MLCK and myosin are widely expressed in the nervous system, facilitation of endocytosis by MLCK/myosin may not be limited to the calyx. In the mouse motor nerve terminals, MLCK/myosin sustains high-frequency neurotransmission by activating a rapid reuse mode of vesicle cycling (MaenoHikichi et al., 2011). Whether this rapid reuse results from accelerated endocytosis is an interesting question to explore. Like most neurophysiology studies, the current paper has relied on using selective blockers to disrupt MLCK/myosin functions. Since the global deletion of MLCK, myosin IIA, or myosin IIB is lethal at birth, future studies using cultured embryonic neurons and conditional knock-out animals will be necessary to study the role of MLCK/myosin in endocytosis on the basis of specifically controlled expression of MLCK and myosin. Indeed, a new study reports that knock-out of myosin IIB decreases activitydependent uptake of FM1-43 and horseradish peroxidase in cultured hippocampal neurons (Chandrasekar et al., 2013), suggesting that MLCK/myosin positively modulates endocytosis across different synapses.

\section{Possible mechanisms underlying the facilitation of endocytosis by MLCK/myosin}

Inhibitors of MLCK/myosin reduced endocytosis kinetics without affecting $\mathrm{Ca}^{2+}$ current (Fig. 7) and $\Delta C_{\mathrm{m}}$ following depolarization (Figs. 1, 3, 4, 6), indicating that MLCK functions downstream of $\mathrm{Ca}^{2+}$ and vesicle fusion in regulating endocytosis. MLCK is typically activated by $\mathrm{Ca}^{2+} /$ calmodulin and can phosphorylate the regulatory light chain of myosin, which triggers interaction between myosin and actin. Although MLCK may also be directly or indirectly activated by other molecules such as the neural cell adhesion molecule (Polo-Parada et al., 2005), protein kinase C (Maeno-Hikichi et al., 2011), Rho/Rho-kinase (Garcia et al., 1999), and p21-activated kinases (Sanders et al., 1999), its modulation of synaptic endocytosis most likely involves $\mathrm{Ca}^{2+}$ / calmodulin that has been indicated to regulate endocytosis in neurons (Wu et al., 2009; Sun et al., 2010; Yamashita et al., 2010; Yao and Sakaba, 2012) and neuroendocrine cells (Artalejo et al., 1996). Calmodulin inhibition at the calyx impairs distinct forms of endocytosis induced by different stimulation paradigms ( $\mathrm{Wu}$ et al., 2009; Yamashita et al., 2010; Yao and Sakaba, 2012), including slow and rapid endocytosis (Wu et al., 2009; Yamashita et al., 

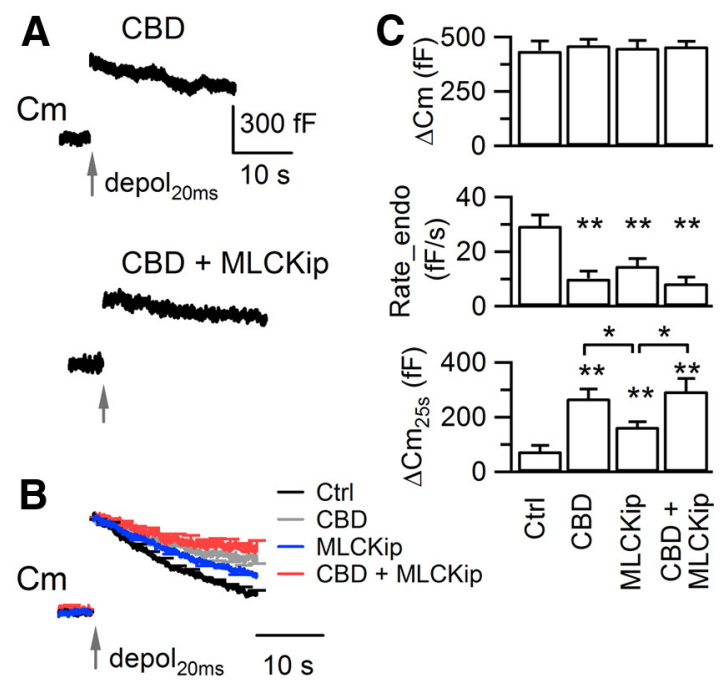
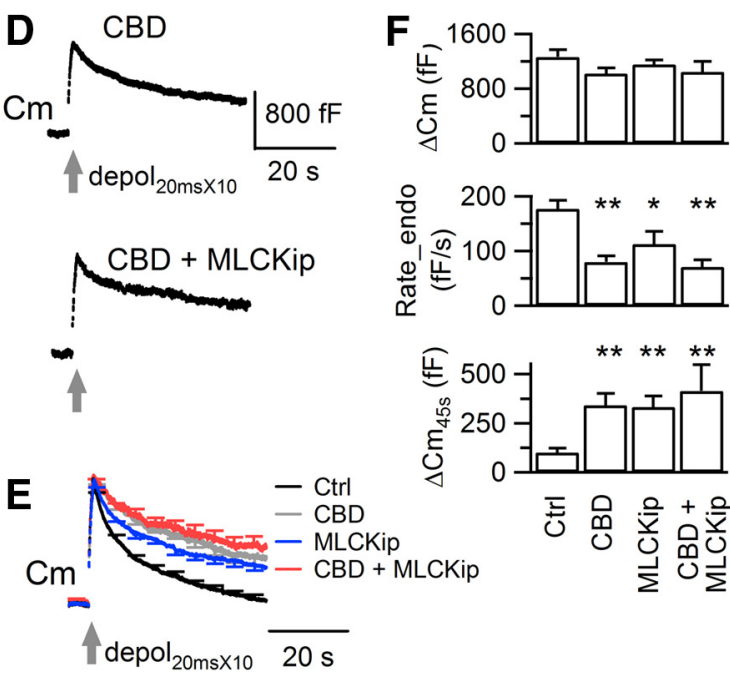

Figure 8. Simultaneous inhibition of calmodulin and MLCK does not induce additive inhibition of endocytosis. $A$, Sampled $C_{m}$ changes induced by depol $\left.\right|_{20 m s}$ from calyces dialyzed with the pipette solution containing CBD $(500 \mu \mathrm{m})$ along with or without MLCKip $(2 \mu \mathrm{M})$. B. Averaged $C_{\mathrm{m}}$ responses induced by depol ${ }_{20 \mathrm{~ms}}$ in control $(n=10), \mathrm{CBD}(n=8), \operatorname{MLCKip}(n=10)$, and CBD with MLCKip $(n=8)$, with the error bars indicating SEM. Individual $C_{\mathrm{m}}$ traces were normalized by $\Delta C_{\mathrm{m}}$ before averaging. Data of control and MLCKip are from the same tests as shown in Figure 1 . $C$, $C$ omparison of $\Delta C_{m}$, Rate_endo, and $\Delta C_{25 s}$ induced by depol ${ }_{20 \mathrm{~ms}}$. $D$, Sampled $C_{\mathrm{m}}$ changes induced by depol ${ }_{20 \mathrm{~ms} \times 10}$ from calyces dialyzed with CBD and/or MLCKip. $\boldsymbol{E}$, Averaged $C_{\mathrm{m}}$ responses induced by depol $_{20 \mathrm{~ms} \times 10}$ in control $(n=10), \mathrm{CBD}(n=7), \operatorname{MLCKip}(n=10)$, and CBD with MLCKip $(n=6)$, which are indicated by the same colors as in $\boldsymbol{B}$. Data of control and MLCKip are from the same tests as shown in Figure 4. Individual $C_{\mathrm{m}}$ traces were normalized by $\Delta C_{\mathrm{m}}$ before averaging. $F$, Comparison of $\Delta C_{\mathrm{m}}$, Rate_endo and $\Delta \mathrm{Cm}_{25 \mathrm{~s}}$ induced by depol ${ }_{20 \mathrm{~ms} \times 10}$.

2010). Consistently, we observed a calmodulin inhibitor, CBD, significantly reduced slow and rapid endocytosis (Fig. 8). Combining CBD and MLCKip did not induce further inhibition of endocytosis (Fig. 8), suggesting that both inhibitors target the same mechanism of endocytosis. Therefore, we think that MLCK accelerates endocytosis downstream of $\mathrm{Ca}^{2+} /$ calmodulin.

A phosphatase downstream of $\mathrm{Ca}^{2+} /$ calmodulin, calcineurin, has been indicated to regulate endocytosis in the calyx and hippocampal boutons (Sun et al., 2010; Yamashita et al., 2010), probably by phosphorylation of dynamin (Liu et al., 1994). We confirmed the involvement of calcineurin in rapid and slow endocytosis by reproducing inhibitory effects of a calcineurin blocker, cyclosporin A (data not shown). Our new finding thus suggests that calmodulin can activate different pathways to regulate endocytosis. Activation of MLCK can phosphorylate myosin, which interacts with actin. In our experiments, blocking myosin II with blebbistatin impaired both slow and rapid endocytosis (Figs. 3, 6). Blebbistatin and deletion of myosin IIB also inhibit endocytosis in hippocampal synapses (Chandrasekar et al., 2013). Although a role of actin in endocytosis is not yet established at mammalian central synapses (Sankaranarayanan et al., 2003), it has been demonstrated in other synapses and nonneuronal cells (Brodin et al., 2000; Merrifield et al., 2005; Girao et al., 2008; Mooren et al., 2012). In the lamprey synapses, actindepolymerizing agents can inhibit clathrin-mediated endocytosis and arrest clathrin-coated pits on the plasma membrane (Shupliakov et al., 2002; Bourne et al., 2006). Inhibitors of actin cytoskeleton also impair clathrin-independent endocytosis in pancreatic $\beta$ cells (He et al., 2008). Actin may assist in detaching vesicle membrane from the plasma membrane along with dynamin (Lee and De Camilli, 2002; Schafer, 2002; Gu et al., 2010). Like dynamin inhibition, disruption of actin polymerization delays the closure of fission pores to retrieve vesicle membrane in chromaffin cells, suggesting that actin indeed regulates the last step of endocytosis (Yao et al., 2013). Based on these results, we suggest that MLCK/myosin facilitates synaptic vesicle endocytosis by functioning between $\mathrm{Ca}^{2+} /$ calmodulin and actin. The
MLCK/myosin pathway and the calcineurin pathway may cooperatively regulate vesicle scission through actin and dynamin, respectively. Because the blockers caused similar partial inhibition of endocytosis, it is difficult to pharmacologically determine the relative contributions of these two pathways downstream of $\mathrm{Ca}^{2+} /$ calmodulin. A future approach is to test inhibitors on synapses from animals lacking MLCK, myosin II, or calcineurin (subunits).

\section{Significance of MLCK/myosin in synaptic transmission}

The current study assigns acceleration of endocytosis as a new role for MLCK/myosin, which was first proposed to function in nerve terminals two decades ago (Mochida et al., 1994). Because endocytosis supports neurotransmission by removing fused vesicle membrane from release sites and by recycling vesicles for future exocytosis (Hosoi et al., 2009; Wu et al., 2009; Hua et al., 2013), an enhancement role in endocytosis predicts contribution of MLCK/myosin to vesicle cycling and synaptic strength during sustained activity, which is compatible with the reported functions of MLCK/myosin in synaptic physiology.

The current literature suggests that MLCK/myosin facilitates vesicle mobilization for release in nerve terminals. Inhibition of MLCK/myosin inhibits high-frequency neurotransmission in motor neurons (Maeno-Hikichi et al., 2011; Seabrooke and Stewart, 2011), and reduces vesicle trafficking and exocytosis in hippocampal neurons (Ryan, 1999), which was later suggested to result from nonspecific inhibition of $\mathrm{Ca}^{2+}$ current (Tokuoka and Goda, 2006). At the calyx, MLCK/myosin inhibitors decrease post-tetanic potentiation following high-frequency action potential firing, without changing $\mathrm{Ca}^{2+}$ current (Lee et al., 2008, 2010). The effect is attributed to impaired recruitment of fast-releasing vesicles, which depends on $\mathrm{Ca}^{2+} /$ calmodulin (Sakaba and Neher, 2001) and actin (Sakaba and Neher, 2003). Because vesicle replenishment and endocytosis both require $\mathrm{Ca}^{2+} /$ calmodulin and $\mathrm{MLCK} / \mathrm{myosin}$, one may wonder whether replenishment of fastreleasing vesicles depends on the speed of endocytosis. However, this possibility is excluded by the finding that inhibition of pro- 
tein kinase A slows endocytosis but not vesicle replenishment (Yao and Sakaba, 2012). In addition, vesicles recruited for release are reported to come from a large recycling pool (Xue et al., 2013), instead of the pool of new vesicles generated from endocytosis ( $\mathrm{Wu}$ and $\mathrm{Wu}, 2009)$. In light of these studies, it is possible that MLCK/myosin facilitates vesicle endocytosis and mobilizes vesicles for release independently.

Meanwhile, MLCK is found to negatively regulate basal neurotransmission. Blocking MLCK activity in the calyx increases the number of fast-releasing vesicles and facilitates the EPSCs evoked by the early action potentials during a train stimulus (Srinivasan et al., 2008; Lee et al., 2010). Similarly, MLCK blockers can antagonize the reduction of releasable vesicles caused by inhibition of Rho kinase in hypoglossal motor synapses (González-Forero et al., 2012). These observations suggest that constitutive activity of MLCK limits the number of vesicles acquiring high priority in fusion. Based on the seemingly paradoxical effects of MLCK inhibitors in vesicle cycling and basal release, we speculate that the constitutive activity of MLCK restricts consumption of vesicles in the readily releasable pool, and activation of MLCK by $\mathrm{Ca}^{2+} /$ calmodulin accelerates both vesicle regeneration via endocytosis and vesicle replenishment from an existing pool. The different functions of MLCK help nerve terminals to maintain continuous supply of releasable vesicles in an activity-dependent manner. To summarize, the present study suggests that activation of MLCK/myosin accelerates the $\mathrm{Ca}^{2+} /$ calmodulin-dependent vesicle endocytosis in synapses, which can contribute to sustaining the neurotransmission during repetitive activity.

\section{References}

Araki N, Hatae T, Furukawa A, Swanson JA (2003) Phosphoinositide-3kinase-independent contractile activities associated with Fcgammareceptor-mediated phagocytosis and macropinocytosis in macrophages. J Cell Sci 116:247-257. Medline

Artalejo CR, Elhamdani A, Palfrey HC (1996) Calmodulin is the divalent cation receptor for rapid endocytosis, but not exocytosis, in adrenal chromaffin cells. Neuron 16:195-205. CrossRef Medline

Bourne J, Morgan JR, Pieribone VA (2006) Actin polymerization regulates clathrin coat maturation during early stages of synaptic vesicle recycling at lamprey synapses. J Comp Neurol 497:600-609. Medline

Brodin L, Löw P, Shupliakov O (2000) Sequential steps in clathrinmediated synaptic vesicle endocytosis. Curr Opin Neurobiol 10:312-320. Medline

Catterall WA, Leal K, Nanou E (2013) Calcium channels and short-term synaptic plasticity. J Biol Chem 288:10742-10749. Medline

Chandrasekar I, Huettner JE, Turney SG, Bridgman PC (2013) Myosin II regulates activity-dependent compensatory endocytosis at central synapses. J Neurosci 33:16131-16145. CrossRef Medline

Dick IE, Tadross MR, Liang H, Tay LH, Yang W, Yue DT (2008) A modular switch for spatial $\mathrm{Ca}^{2+}$ selectivity in the calmodulin regulation of $\mathrm{CaV}$ channels. Nature 451:830-834. CrossRef Medline

Fioravante D, Chu Y, Myoga MH, Leitges M, Regehr WG (2011) Calciumdependent isoforms of protein kinase $\mathrm{C}$ mediate posttetanic potentiation at the calyx of Held. Neuron 70:1005-1019. CrossRef Medline

Garcia JG, Verin AD, Schaphorst K, Siddiqui R, Patterson CE, Csortos C, Natarajan V (1999) Regulation of endothelial cell myosin light chain kinase by Rho, cortactin, and p60(src). Am J Physiol 276:L989-L998. Medline

Girao H, Geli MI, Idrissi FZ (2008) Actin in the endocytic pathway: from yeast to mammals. FEBS Lett 582:2112-2119. Medline

González-Forero D, Montero F, García-Morales V, Domínguez G, GómezPerez L, García-Verdugo JM, Moreno-López B (2012) Endogenous Rho-kinase signaling maintains synaptic strength by stabilizing the size of the readily releasable pool of synaptic vesicles. J Neurosci 32:68-84. CrossRef Medline

Gu C, Yaddanapudi S, Weins A, Osborn T, Reiser J, Pollak M, Hartwig J, Sever
S (2010) Direct dynamin-actin interactions regulate the actin cytoskeleton. EMBO J 29:3593-3606. Medline

He L, Xue L, Xu J, McNeil BD, Bai L, Melicoff E, Adachi R, Wu LG (2009) Compound vesicle fusion increases quantal size and potentiates synaptic transmission. Nature 459:93-97. CrossRef Medline

He Z, Fan J, Kang L, Lu J, Xue Y, Xu P, Xu T, Chen L (2008) $\mathrm{Ca}^{2+}$ triggers a novel clathrin-independent but actin-dependent fast endocytosis in pancreatic beta cells. Traffic 9:910-923. CrossRef Medline

Hosoi N, Holt M, Sakaba T (2009) Calcium dependence of exo- and endocytotic coupling at a glutamatergic synapse. Neuron 63:216-229. CrossRef Medline

Hua Y, Woehler A, Kahms M, Haucke V, Neher E, Klingauf J (2013) Blocking endocytosis enhances short-term synaptic depression under conditions of normal availability of vesicles. Neuron 80:343-349. CrossRef Medline

Kovács M, Tóth J, Hetényi C, Málnási-Csizmadia A, Sellers JR (2004) Mechanism of blebbistatin inhibition of myosin II. J Biol Chem 279:3555735563. Medline

Lee E, De Camilli P (2002) Dynamin at actin tails. Proc Natl Acad Sci USA 99:161-166. CrossRef Medline

Lee JS, Kim MH, Ho WK, Lee SH (2008) Presynaptic release probability and readily releasable pool size are regulated by two independent mechanisms during posttetanic potentiation at the calyx of Held synapse. J Neurosci 28:7945-7953. CrossRef Medline

Lee JS, Ho WK, Lee SH (2010) Post-tetanic increase in the fast-releasing synaptic vesicle pool at the expense of the slowly releasing pool. J Gen Physiol 136:259-272. Medline

Lindau M, Neher E (1988) Patch-clamp techniques for time-resolved capacitance measurements in single cells. Pflugers Arch 411:137-146. Medline

Liu JP, Sim AT, Robinson PJ (1994) Calcineurin inhibition of dynamin I GTPase activity coupled to nerve terminal depolarization. Science 265: 970-973. CrossRef Medline

Lukas TJ, Mirzoeva S, Slomczynska U, Watterson DM (1999) Identification of novel classes of protein kinase inhibitors using combinatorial peptide chemistry based on functional genomics knowledge. J Med Chem 42 : 910-919. Medline

Maeno-Hikichi Y, Polo-Parada L, Kastanenka KV, Landmesser LT (2011) Frequency-dependent modes of synaptic vesicle endocytosis and exocytosis at adult mouse neuromuscular junctions. J Neurosci 31:1093-1105. CrossRef Medline

Mansfield PJ, Shayman JA, Boxer LA (2000) Regulation of polymorphonuclear leukocyte phagocytosis by myosin light chain kinase after activation of mitogen-activated protein kinase. Blood 95:2407-2412. Medline

Marchiando AM, Shen L, Graham WV, Weber CR, Schwarz BT, Austin JR 2nd, Raleigh DR, Guan Y, Watson AJ, Montrose MH, Turner JR (2010) Caveolin-1-dependent occludin endocytosis is required for TNF-induced tight junction regulation in vivo. J Cell Biol 189:111-126. Medline

Merrifield CJ, Perrais D, Zenisek D (2005) Coupling between clathrincoated-pit invagination, cortactin recruitment, and membrane scission observed in live cells. Cell 121:593-606. CrossRef Medline

Mochida S, Kobayashi H, Matsuda Y, Yuda Y, Muramoto K, Nonomura Y (1994) Myosin II is involved in transmitter release at synapses formed between rat sympathetic neurons in culture. Neuron 13:1131-1142. CrossRef Medline

Mooren OL, Galletta BJ, Cooper JA (2012) Roles for actin assembly in endocytosis. Annu Rev Biochem 81:661-686. CrossRef Medline

Nairn AC, Picciotto MR (1994) Calcium/calmodulin-dependent protein kinases. Semin Cancer Biol 5:295-303. Medline

Nakanishi S, Kakita S, Takahashi I, Kawahara K, Tsukuda E, Sano T, Yamada K, Yoshida M, Kase H, Matsuda Y, Hashimoto Y, and Nonomuran Y (1992) Wortmannin, a microbial product inhibitor of myosin light chain kinase. J Biol Chem 267:2157-2163. Medline

Polo-Parada L, Plattner F, Bose C, Landmesser LT (2005) NCAM 180 acting via a conserved C-terminal domain and MLCK is essential for effective transmission with repetitive stimulation. Neuron 46:917-931. CrossRef Medline

Poskanzer KE, Marek KW, Sweeney ST, Davis GW (2003) Synaptotagmin I is necessary for compensatory synaptic vesicle endocytosis in vivo. Nature 426:559-563. CrossRef Medline

Renden R, von Gersdorff H (2007) Synaptic vesicle endocytosis at a CNS nerve terminal: faster kinetics at physiological temperatures and increased 
endocytotic capacity during maturation. J Neurophysiol 98:3349-3359. CrossRef Medline

Ryan TA (1999) Inhibitors of myosin light chain kinase block synaptic vesicle pool mobilization during action potential firing. J Neurosci 19:13171323. Medline

Saitoh M, Ishikawa T, Matsushima S, Naka M, Hidaka H (1987) Selective inhibition of catalytic activity of smooth muscle myosin light chain kinase. J Biol Chem 262:7796-7801. Medline

Sakaba T, Neher E (2001) Calmodulin mediates rapid recruitment of fastreleasing synaptic vesicles at a calyx-type synapse. Neuron 32:1119-1131. CrossRef Medline

Sakaba T, Neher E (2003) Involvement of actin polymerization in vesicle recruitment at the calyx of Held synapse. J Neurosci 23:837-846. Medline

Sanders LC, Matsumura F, Bokoch GM, de Lanerolle P (1999) Inhibition of myosin light chain kinase by p21-activated kinase. Science 283:20832085. CrossRef Medline

Sankaranarayanan S, Ryan TA (2001) Calcium accelerates endocytosis of vSNAREs at hippocampal synapses. Nat Neurosci 4:129-136. Medline

Sankaranarayanan S, Atluri PP, Ryan TA (2003) Actin has a molecular scaffolding, not propulsive, role in presynaptic function. Nat Neurosci 6:127135. Medline

Schafer DA (2002) Coupling actin dynamics and membrane dynamics during endocytosis. Curr Opin Cell Biol 14:76-81. Medline

Schwarz BT, Wang F, Shen L, Clayburgh DR, Su L, Wang Y, Fu YX, Turner JR (2007) LIGHT signals directly to intestinal epithelia to cause barrier dysfunction via cytoskeletal and endocytic mechanisms. Gastroenterology 132:2383-2394. CrossRef Medline

Seabrooke S, Stewart BA (2011) Synaptic transmission and plasticity are modulated by nonmuscle myosin II at the neuromuscular junction of Drosophila. J Neurophysiol 105:1966-1976. CrossRef Medline

Shupliakov O, Bloom O, Gustafsson JS, Kjaerulff O, Low P, Tomilin N, Pieribone VA, Greengard P, Brodin L (2002) Impaired recycling of synaptic vesicles after acute perturbation of the presynaptic actin cytoskeleton. Proc Natl Acad Sci USA 99:14476-14481. CrossRef Medline

Srinivasan G, Kim JH, von Gersdorff H (2008) The pool of fast releasing vesicles is augmented by myosin light chain kinase inhibition at the calyx of Held synapse. J Neurophysiol 99:1810-1824. CrossRef Medline

Sun JY, Wu LG (2001) Fast kinetics of exocytosis revealed by simultaneous measurements of presynaptic capacitance and postsynaptic currents at a central synapse. Neuron 30:171-182. CrossRef Medline

Sun T, Wu XS, Xu J, McNeil BD, Pang ZP, Yang W, Bai L, Qadri S, Molkentin JD, Yue DT, Wu LG (2010) The role of calcium/calmodulin-activated calcineurin in rapid and slow endocytosis at central synapses. J Neurosci 30:11838-11847. CrossRef Medline

Tokuoka H, Goda Y (2006) Myosin light chain kinase is not a regulator of synaptic vesicle trafficking during repetitive exocytosis in cultured hippocampal neurons. J Neurosci 26:11606-11614. CrossRef Medline

Wu W, Xu J, Wu XS, Wu LG (2005) Activity-dependent acceleration of endocytosis at a central synapse. J Neurosci 25:11676-11683. CrossRef Medline

Wu XS, Wu LG (2009) Rapid endocytosis does not recycle vesicles within the readily releasable pool. J Neurosci 29:11038-11042. CrossRef Medline

Wu XS, McNeil BD, Xu J, Fan J, Xue L, Melicoff E, Adachi R, Bai L, Wu LG (2009) $\mathrm{Ca}^{2+}$ and calmodulin initiate all forms of endocytosis during depolarization at a nerve terminal. Nat Neurosci 12:1003-1010. Medline

$\mathrm{Xu} \mathrm{J,} \mathrm{Wu} \mathrm{LG} \mathrm{(2005)} \mathrm{The} \mathrm{decrease} \mathrm{in} \mathrm{the} \mathrm{presynaptic} \mathrm{calcium} \mathrm{current} \mathrm{is} \mathrm{a}$ major cause of short-term depression at a calyx-type synapse. Neuron 46:633-645. CrossRef Medline

Xu J, McNeil B, Wu W, Nees D, Bai L, Wu LG (2008) GTP-independent rapid and slow endocytosis at a central synapse. Nat Neurosci 11:45-53. Medline

Xu J, Luo F, Zhang Z, Xue L, Wu XS, Chiang HC, Shin W, Wu LG (2013) SNARE proteins synaptobrevin, SNAP-25, and syntaxin are involved in rapid and slow endocytosis at synapses. Cell Rep 3:1414-1421. Medline

Xue L, Wu LG (2010) Post-tetanic potentiation is caused by two signalling mechanisms affecting quantal size and quantal content. J Physiol 588: 4987-4994. CrossRef Medline

Xue L, Zhang Z, McNeil BD, Luo F, Wu XS, Sheng J, Shin W, Wu LG (2012) Voltage-dependent calcium channels at the plasma membrane, but not vesicular channels, couple exocytosis to endocytosis. Cell Rep 1:632-638. Medline

Xue L, Sheng J, Wu XS, Wu W, Luo F, Shin W, Chiang HC, Wu LG (2013) Most vesicles in a central nerve terminal participate in recycling. J Neurosci 33:8820-8826. CrossRef Medline

Yamashita T, Hige T, Takahashi T (2005) Vesicle endocytosis requires dynamin-dependent GTP hydrolysis at a fast CNS synapse. Science 307: 124-127. CrossRef Medline

Yamashita T, Eguchi K, Saitoh N, von Gersdorff H, Takahashi T (2010) Developmental shift to a mechanism of synaptic vesicle endocytosis requiring nanodomain $\mathrm{Ca}^{2+}$. Nat Neurosci 13:838-844. Medline

Yao L, Sakaba T (2012) Activity-dependent modulation of endocytosis by calmodulin at a large central synapse. Proc Natl Acad Sci USA 109:291296. CrossRef Medline

Yao LH, Rao Y, Varga K, Wang CY, Xiao P, Lindau M, Gong LW (2012) Synaptotagmin 1 is necessary for the $\mathrm{Ca}^{2+}$ dependence of clathrinmediated endocytosis. J Neurosci 32:3778-3785. CrossRef Medline

Yao LH, Rao Y, Bang C, Kurilova S, Varga K, Wang CY, Weller BD, Cho W, Cheng J, Gong LW (2013) Actin polymerization does not provide direct mechanical forces for vesicle fission during clathrin-mediated endocytosis. J Neurosci 33:15793-15798. CrossRef Medline 